\title{
Autoficção e intermidialidade na cena contemporânea
}

Autoficcion and intermidiality in the contemporary scene

Andréa Stelzer ${ }^{1}$ 


\section{Resumo}

$\mathrm{Na}$ cena contemporânea brasileira e latino-americana, assistimos a um crescente interesse pelo relato biográfico como parte inerente da criação dramatúrgica. As narrativas partem da vida pessoal dos atores e são ficcionalizadas no palco buscando uma relação com a intermidialidade como forma de buscar uma singularidade. Neste texto, analiso dois espetáculos autoficcionais: Conversas com meu pai, da atriz Janaína Leite e Melancolia y manifestaciones, da argentina Lola Arias a fim de refletir sobre as diferentes formas de trabalhar com a memória e as subjetividades na cena.

Palavras-chave: Autoficção; intermidialidade; cena contemporânea; subjetivação

\section{Abstract}

In the Brazilian and Latin American contemporary scene, we see an increasing interest in the biographical speeches as an inherent part of the dramaturgical creation. The narratives starts from the personal lives of the actors and are fictionalized on the stage seeking a relation with intermediality as a way to find singularity. This paper makes an analysis of two autoficcional spectacles: Conversas com meu pai of the brasilian Janaína Leite and Melancolia y manifestaciones of the argentine Lola Arias to reflect on the different ways of working with memory and subjectivity in the scene.

Keywords: Autofiction; intermediality; contemporary scene; subjectivity 


\section{Introdução}

A questão da cena documental envolve diversos fatores que se articulam com os acontecimentos mais específicos de nossa época como: as narrativas do outro, a relação com a alteridade, o estudo etnográfico (das diferentes etnias) e sociológico, os ensaios políticos, as narrativas biográficas ou autobiográficas.

A intensificação das subjetividades na cena contemporânea se expressa através das experiências pessoais como objeto das obras que vão além de uma mera inspiração, à medida que tais relatos assumem forma dramatizada. Unido aos processos de hibridização discursiva (convergência de distintos gêneros, diversificação das formas de autorepresentação, problematização da dualidade factual-ficcional, inclusão de novos suportes e mídia), isso explica, neste momento concreto de nossa história, a emergência e o desenvolvimento dos relatos autoficcionais.

Nota-se um grande interesse em narrativas autoficcionais quando as diferentes subjetividades passaram a interessar como uma nova cartografia de estudos sociais, etnográficos e das micropolíticas que formam a sociedade. As subjetividades aparecem na cena como meio de contestar uma verdade única produzida pela mídia e pelos que estão no poder e desejam estabelecer novas cartografias com olhares renovados sobre a história. Essas narrativas têm o desejo de resistir às imagens embaralhadas criadas pela mídia, que apresenta os acontecimentos como um espetáculo distanciado da realidade, e buscam refundar os conceitos éticos de uma arte política e transformadora no nível dos afetos.

O pesquisador Silviano Santiago $(2002$, p.39) associava a explicitação do componente autobiográfico e memorialista na prosa do início dos anos 70, época de retorno dos exilados e de abertura democrática, de maneira que o romance perdia seu estatuto de ficção e ia ganhando cores de depoimento. Havia um deslocamento do fingimento e da imaginação para a memória afetiva e a experiência pessoal do escritor. Santiago apontava para a importante função desses discursos como forma de deixar falar o Outro, num momento em que a questão das minorias, a repressão do sujeito, a negação da diferença e da liberdade pessoal se tornavam visíveis no contexto brasileiro.

Outra questão importante é a tensão entre real e ficção nas narrativas documentais ao se distinguir de uma obra realista, em que também é possível trabalhar-se com documentos, porém a narrativa documental se expõe como documento provocando o efeito de ruptura e suspensão, pela inserção de documentos que expõem uma hiperealidade, mais sensível que a lógica fabular do realismo. Ou ainda, segundo Beatriz Resende (2014), o real rasura o ficcional ao apresentar testemunhos, relatos e documentos reais misturados com a escrita ficcional.

Por outro lado, ficcionalizar os dados de composição de biografias ou autobiografias significa considerá-los como metáforas, ordená-los de forma narrativa, sem que haja qualquer desvio em relação à verdade factual, conforme destacou Rancière, em Partilha do sensível, sobre o conceito de ficção:

$\mathrm{O}$ real precisa ser ficcionado para ser pensado. A política e a arte, tanto quanto os saberes, constroem ficções, isto é, rearranjos materiais dos signos e das imagens, das relações entre o que se diz, entre o que se faz e o que se pode fazer. (Rancière, 2005, p.53-59) 
Sendo assim, o que importa na cena autoficcional não é definir o que é real e ficção nas distintas produções, mas sim investigar as diferentes poéticas que estabelecem um jogo com o real e a ficção estimulando uma participação ativa do espectador na cena. Inicialmente, torna-se necessário refletir acerca dos conceitos de autobiografia e autoficção como condição essencial para se pensar na produção de um discurso artístico sobre as biografias criadas pelas duas atrizes e encenadoras (brasileira Janaina Leite e argentina Lola Arias) e o processo de construção cênicol dramatúrgico baseado nos fatos das suas próprias vidas.

\section{Autobiografia elou autoficção?}

Em 1970, na França, teve início uma ampla discussão sobre as narrativas de cunho autobiográfico, refutando, sobretudo, as ideias de Philippe Lejeune, conhecido por seus estudos em torno da autobiografia. A autobiografia, segundo Lejeune, pressupõe a veracidade dos fatos e o compromisso com a realidade através de um "pacto autobiográfico", isto é, um pacto de autenticidade em que não há dúvidas a respeito da identidade entre as instâncias do narrador, protagonista e autor.

Por outro lado, Serge Doubrovsky, em 1977, cria o termo autofiction, por considerar que, ainda que em primeira pessoa e a partir de experiências vividas, a escrita será sempre um "ato estetizado e ficcional", e aponta a autoficção como a possibilidade de se transitar entre a autobiografia, o discurso referencial e a ficção, tendo a figura do autor plasmada na do narrador.

A questão principal seria: Por que falar de si próprio? Que impulso é esse que anima o desejo de contar a própria vida? Léonor Arfuch defende o que ela chama de valor biográfico ao sublinhar a possibilidade de ordenar "a vivência da própria vida" e conectá-la, enquanto singularidade. A autora fala desse "algo que se destaca do fluxo ininterrupto da vida e fica como rastro perdurável" (Arfuch , 2009, p. 118). Outra possível reflexão seria que a autoficção é um gênero próprio da pós-modernidade, conforme leitura de Doubrovsky citada por Eurídice Figueiredo:

A autoficção, tal como concebida por Doubrovsky, seria uma variante pós-moderna da autobiografia na medida em que ela não acredita mais numa verdade literal, numa referência indubitável, num discurso histórico coerente e se sabe reconstrução arbitrária e literária de fragmentos esparsos da memória. Outro aspecto importante é a questão da linguagem: quem faz autoficção hoje não narra simplesmente o desenrolar dos fatos, preferindo, antes, deformá-los, reformá-los, através de artifícios. (Figueiredo, 2013, p. 62)

Importante observar que a emergência de textos autoficcionais que problematizam a noção de verdade e colocam em xeque a autoridade do discurso dialoga diretamente com as novas configurações do sujeito contemporâneo, cindido em sua identidade fragmentada e contraditória. E, por outro lado, analisando o processo de construção da noção de indivíduo na modernidade, conforme nos recorda a crítica argentina Leonor Arfuch, não se pode esquecer que "confissões, autobiografias, me- 
mórias, diários íntimos, correspondências, traçariam, para além de seu valor literário intrínseco, um espaço de autorreflexão decisivo para a consolidação da individualidade como um dos traços típicos do Ocidente." (Arfuch, 2010, p. 36).

Por outro lado essas narrativas biográficas e autoficcionais buscam novas formas de tencionar o real e a ficção, o presente e o passado, a performance e a representação por meio da intermidialidade, ou seja, das novas mídias digitais que vem se hibridizando nas artes contemporâneas de um modo geral. As mídias livro, TV e câmera evidentemente exercem um poder de outra natureza, que não passa necessariamente pelo conteúdo dos discursos, mas sim pela forma, o que nos direciona a novas experiências perceptivas e discursivas, como leitores e escritores de linguagens.

O conceito de mídia (meio, mediação) tomado pela Teoria da Mídia aproxima-se ao de dispositivo, e não somente porque hoje se faz uma ligação quase que natural entre mídia massiva e poder. Por mídia entende-se tanto meio de comunicação de massa como suporte, sentidos comuns ao brasileiro, como meio, mediação ou rede (num sentido semelhante ao de dispositivo). Assim, tanto a literatura (dispositivo) como o livro (suporte) são mídias, e tanto o cinema como um filme também o são, conforme explicitou Muller:

Literatura e cinema devem ser entendidos como mídias que se inter-relacionam de modos diversos, dentro de um universo midiático bastante amplo, que inclui mídias diversas, como a tradição oral, a canção popular, o rádio, a imprensa escrita, a televisão, as artes visuais, a internet, o videogame, etc. O estudo dessas inter-relações configura o campo da intermidialidade. (Muller, 2012, p.169)

A intermidialidade consiste num hibridismo entre mídias diversas como: o documento no filme (nos filmes documentários), a teatralidade no cinema em filmes como os de Glauber Rocha ou os de Fellini (que revelam os signos de teatralidade nos personagens pelo exagero e pela exposição dos artifícios do cenário), o cinema no teatro como no espetáculo Os náufragos da louca esperança (2011) em que Mnouchkine encena o nascimento do cinema entrecruzando imagens de arquivo com a câmera filmando ao mesmo tempo a cena dos atores no presente.

Sendo assim, este texto analisa como os espetáculos criam um hibridismo entre as diferentes mídias a fim de auxiliar na escrita de si e proceder a um processo de singularização, conforme será observado nas diferentes formas de construção da cena autoficcional das atrizes.

\section{A cena autoficcional de Janaína Leite em Conversas com meu pai}

Tendo como horizonte de questões as reflexões realizadas acima, proponho uma análise do processo de escrita cênica/dramatúrgica da atriz Janaína Leite no espetáculo Conversas com meu pai discutindo questões tais como: até que ponto a autobiografia também não é uma produção ficcional da atriz? De que forma é trabalhada a memória da atriz na cena? Como esta cena pode ser interessante para o espectador?

O espetáculo Conversas com meu pai estreou em 2014 no Sesc de Copacabana no Rio de Janeiro resultado de um longo processo de acúmulo de arquivos de 
memória da relação da atriz Janaína Leite com seu pai, no momento em que ele não conseguia mais falar devido a uma operação na garganta, assim a sua comunicação com ele nos últimos 7 anos de vida passou a ser silenciosa. O espetáculo trata de resolver um trauma da atriz, de um possível incesto, mas que ela não tem certeza se ocorreu, resultando numa mistura entre memória e imaginação, real e simbólico levando o espectador a um processo investigativo do início ao fim.

Em Conversas com meu pai não é possível afirmar que exista uma escrita autobiográfica em essência, na qual atriz e personagem sejam uma só. A atriz não chega a narrar a história que ocorreu com seu pai, mas sua narrativa é interrompida o tempo todo pelo seu fluxo de pensamento que questiona o porquê de estar ali fazendo uma peça autobiográfica. Ela começa a peça num tom confessional dizendo para o público que quer contar um segredo, mas que não sabe se realmente aconteceu. A partir daí, o pacto autobiográfico é colocado em dúvida e cria-se um distanciamento que faz com que o público reflita e tente decifrar o que é verdade ou imaginação.

O espaço é dividido em duas partes: na primeira, a atriz confessa que tem um segredo a contar, mas que nem ela sabe se é verdade o que aconteceu com seu pai. O público chega e senta em cadeiras num círculo. Ela está sentada, molhada, traja um vestido preto e segura uma caixa na mão com os bilhetinhos do pai, que não falava mais. Porém, ela não abre a caixa porque questiona se isso seria realmente importante para o que ela quer falar ali. Ela quer revelar um segredo que não sabe se realmente aconteceu ou se é parte de sua imaginação, ela se deita no chão e conta um sonho que teve com o pai.

Em seguida, ela chama o público para outro espaço, onde há uma arquibancada, o cenário é cheio de plantas com uma piscina de plástico, buscando recriar a casa do pai, um telão mostra as fotos e os vídeos dos passeios que ela fez com o pai antes de ele morrer. Ela começa a questionar o porquê de estar fazendo um espetáculo autobiográfico, qual o motivo de estar falando de sua vida e em que isso poderia interessar os outros. Ela fala com raiva, fala alto e desafia o espectador num ato de revolta. Esse fluxo de pensamento, que acontece como uma reflexão no presente, interrompe a narrativa da história não permitindo que ela seja contada.

Pode-se pensar que Conversas com meu pai se encaixa mais na noção de espaço biográfico, conforme explicitou Leonor Arfuch (2005), pois parte do reconhecimento do caráter fragmentário e caótico da identidade da atriz. Arfuch sustenta que não há identidade possível entre autor e personagem porque não existe coincidência entre a experiência vivencial e a totalidade artística. Não se trata de uma reprodução mais ou menos fiel de um passado, se trata apenas de literatura.

Nesse sentido, o problema se desloca para o espaço biográfico, no qual o leitor poderá integrar os registros referenciais e ficcionais, onde poderá jogar com os equívocos e tentar decifrar os desdobramentos da identidade, aproximando-se da autoficção conforme explicitou Doubrovsky: "A autoficção é a ficção que eu, como escritor, decidi apresentar de mim mesmo, incorporando, no sentido estrito do termo, a experiência de análise, não somente do tema, mas também da produção do texto." (Klinger, 2012, p.47 apud Doubrovsky, 1988, p.77).

Interessante notar que a autoficção dilui o espaço fronteiriço entre biografia e ficção dando mais importância à construção de um efeito de linguagem que se apro- 
xima da noção de performance, conforme afirmou Klinger: "O autor é considerado como sujeito de uma performance, um sujeito que representa um papel nas suas múltiplas falas de si." (p.50). Para Klinger, a autoficção é o resultado de uma construção que opera tanto na ficção quanto na vida mesma, assim como a performance, de forma que ambas se apresentam como textos inacabados, improvisados, work in progress, como se o leitor assistisse ao vivo o processo de escrita.

Assim, o interessante na autoficção não é uma certa quantidade de verdade dos fatos, mas a ilusão da presença, do acesso ao lugar de emanação da voz, a performance da atriz dentro do espaço biográfico. A atriz em Conversas com meu pai realiza uma construção ficcional e poética de suas memórias, juntando elementos simbólicos e imaginários ao colocar o espectador no jogo de equívocos, buscando decifrar a sua identidade fragmentada.

Conforme a própria Janaína afirmou, em artigo para a revista Sala Preta (2014, p.161), não se trata de um narrar positivado, que tenta fechar os nexos e propor uma experiência de identificação como aquelas proporcionadas pelas narrativas autobiográficas. Na tela do fundo quase vinte minutos de imagens documentais são projetadas nesse cenário-instalação ao mesmo tempo em que a intérprete em cena fala desenfreadamente, explicitando o processo de criação. Texto e vídeos se relacionam sem que, no entanto, se crie uma narrativa linear através deles.

No lugar da identidade entre autor e narrador (que funda o pacto autobiográfico de Lejeune) se exibe uma fissura entre o sujeito do enunciado e o da enunciação que aparece no momento em que a atriz se interroga sobre o que ela realmente está fazendo ali. A perda da memória produz um distúrbio e desestabiliza os princípios do discurso autobiográfico: a sinceridade e a autenticidade. $O$ discurso da atriz se coloca em jogo a partir da indecibilidade entre realidade e ficção, identidade e memória e imaginação, que quebra a continuidade vivida no discurso autobiográfico.

A personagem se exibe ao vivo (ao questionar-se se quer de fato falar de sua vida) no momento mesmo da construção do discurso, indagando tanto sobre a sua subjetividade como posicionando-se de forma crítica perante os seus modos de representação. Ao experimentar o risco de expor-se, a atriz oferece o íntimo, o mais pessoal, que permite ao espectador não ser obrigado a entender o espetáculo, mas apenas vivê-lo, senti-lo e, até mesmo, defini-lo como não teatral, cruzando o plano do performativo.

Pode-se considerar a cena de Janaína Leite como autoficcional por se tratar de uma narrativa híbrida, na qual a ficção de si tem como autor não a pessoa biográfica, mas o autor como personagem construído discursivamente. $O$ arquivo de lembranças reunido pela atriz não é um acúmulo de relatos e documentos da vida de Janaína Leite, mas é o momento de fricção deste real com o imaginário, numa tensão entre memória e esquecimento. É a performance da atriz, ou seja, o jogo que ela cria entre realidade e ficção estruturando uma desnaturalização da narrativa autobiográfica, que oferece o fundamento teórico possível para que o espetáculo possa ser nomeado como um discurso autoficcional. 


\section{Autoficção em Melancolia y Manifestaciones de Lola Arias}

O espetáculo estreou em 2013, na Argentina, e, em 2015, ficou em cartaz no Rio de Janeiro, no Festival Dois Pontos: Brasil e Argentina, onde pude assistir à peça que começa com a projeção de um texto informativo sobre o ponto de partida deste acontecimento teatral: "Esta é uma obra sobre uma filha que quer entender a depressão de sua mãe". Não há nomes próprios nesta pequena projeção na parede, mas vai se construindo um espectador que reconhece a convenção e aceita tanto o pacto biográfico quanto o ficcional de uma vez. O fato de Lola confessar que quer entender a depressão da mãe revela, desde o início, o jogo entre memória e imaginação, presente e passado, público e privado dentro do contexto histórico e político da época da ditadura na Argentina.

A obra apresenta uma estrutura de quadros com o nome de cada episódio projetado com títulos de diferentes capítulos de uma biografia ao vivo: "Prólogo", "As duas caras de minha mãe", "A cama", "O dinheiro", "A acompanhante", etc. A narração de Lola vai sendo tecida como retalhos de crônicas escritas, filmagens, entrevistas e recordações.

O dispositivo cênico é uma estrutura retangular que marca o espaço de representação com uma persiana que, se fechada, projeta imagens reais da mãe e, ao se abrir, apresenta o mundo ficcional representado pelos atores e não atores em cena. Fora desta estrutura estão vários objetos à espera de serem utilizados: roupas, objetos decorativos, caixas de medicamento, um carrinho de supermercado, plantas, escada, mesa e também os performers (não atores da idade da mãe) que aparecem sentados no espaço fora da representação. Há um espaço reservado para o músico que canta e toca violão, e outro, à esquerda, com um microfone, o lugar da narração de Lola que, além de narrar, canta e informa tudo sobre Amélia (sua mãe). Lola Arias vai narrando a história rasurando o real com a ficção:

Essa era a voz da minha mãe, mas ela não é minha mãe. Ela se chama Elvira, professora de teatro. Ela e seus alunos vão ajudar-me a reconstruir a história de minha mãe. Uma equipe de cinco performers de mais de setenta anos serão os atores que representam os distintos papéis e pessoas que passaram pela vida de Amélia: seus amores, psiquiatras, amizades, companheiras de ginástica, etc. (trecho da peça)

Lola estabelece uma poética na encenação que mistura ficção com elementos reais, como ao duplicar a imagem de sua mãe, com uma atriz interpretando seu papel, ao mesmo tempo em que é a voz da própria mãe que ouvimos. As gravações audiovisuais são produto das entrevistas da diretora a sua mãe. As filmagens são momentos de suas distintas atividades que se apresentam como registros documentais. O espetáculo começa com o depoimento de Lola:

Quando eu nasci o ovário de minha mãe explodiu e tudo se cobriu de sangue: a cama, o piso do hospital, a roupa das enfermeiras. Era 1976 e o país também havia explodido. Por sorte minha mãe e eu sobrevivemos. Mas dias depois minha mãe ficou muito triste. Foi a um médico e lhe disseram que esta tristeza se chamava depressão e que devia tomar uns comprimidos para curar-se. (trecho da peça) 
A construção do relato se realiza a partir de uma primeira pessoa que coincide o autor com o narrador. Porém, essa coincidência se realiza não em função de contar a própria vida, mas de contar uma vida alheia, a de sua mãe e a sua relação com ela. Deste modo, o espetáculo entrecruza modos de narrar que podem corresponder ao chamado biografia em primeira pessoa. Ou poder-se-ia dizer um biodrama em primeira pessoa (para usar o termo de Vivi Tellas).

Segundo Lejeune, a biografia em primeira pessoa corresponderia à narrada por um narrador testemunho. Lola é testemunha da vida de sua mãe, de sua doença. Enquanto testemunho pressupõe sempre um fato que preexiste e cuja força e realidade devem ser confirmadas e certificadas. Nesse sentido, Lola aparece como uma autora que faz valer poeticamente tanto a própria experiência quanto a da mãe: desse momento íntimo, do qual ambas sobreviveram, e do início do golpe militar, a cujas consequências continuam sobrevivendo.

Entre a Amélia, representada por Elvira, e a mãe real de Lola existe um playback (com a voz real gravada da mãe) que funciona intermediando tecnologicamente a discordância da ausência e presença das duas Amélias. Desse modo, a linha que se instaurava entre o chamado teatro de ficção e o documental parece tornar-se cada vez menos discernível. Se o relato autobiográfico excluía a possibilidade de construir ficção por meio da identidade entre o nome do personagem e o nome do autor, quando Lola se expressa com seu eu testemunhal e autobiográfico no espetáculo, ela põe em evidência a possibilidade de deslocamento desse pressuposto.

O problema não é tanto a relação entre ficção e real, na medida em que o espectador assume um pacto biográfico pelo qual aceita que o que se conta possui verdade histórica, está vinculado à vida cotidiana e que o espetáculo oferece recursos internos de verificação, por exemplo, entre o dito e o visto. O problema principal está em como os materiais da realidade do acontecido em nosso mundo comum se transformam em uma construção poética, transitória, múltipla, de muitos planos entre a realidade e a poesia.

\section{Conclusão}

O que parece novidade na cena autoficcional não é o pacto estabelecido com o espectador entre o que é real ou ficção, mas o jogo, a performance potente e provocadora das atrizes que torna a sua presença mais significativa do que o sentido da história. A quebra do pacto autobiográfico equivale a uma quebra com relação a expectativas de realidade e de ficção, causando estranhamento e levando o espectador a uma participação ativa para interpretar suas histórias.

O que se apresenta na cena autoficcional de Janaina é o real do trauma, irrepresentável, sobre o qual geralmente se cala; e o ficcional das autoficções caracteriza-se como aquele que se aproxima do imaginário, da memória, do incorpóreo, muito mais do que o fictício da ficção, resultado de processos racionais de seleção e combinação. Trata-se, portanto, de formulações de real e de ficcional essencialmente atravessadas pela subjetividade da atriz.

Em Melancolia y manifestaciones Lola se coloca em cena ao narrar os episódios da vida da mãe pelo cruzamento de documentos reais com a ficção, produzida pela 
encenação de atores e não atores. Lola cria um distanciamento poético a fim de refletir sobre a depressão da mãe, com interrupções, citações, depoimentos, canções, estruturando uma narrativa fragmentada por episódios.

Lola Arias se apossa de um fato histórico da ditadura na Argentina e caminha em direção ao individual. A retomada da história alcança uma política da memória que abre espaço para a recriação pessoal de um tempo que se vê coletivo. As imagens adquirem um estatuto político-afetivo, ao serem apropriadas não para buscar uma verdade dos fatos históricos, mas para recontar o ocorrido pelo viés da memória subjetiva.

Os exercícios das subjetividades na cena contemporânea apresentam um jogo entre palavra e imagem, real e ficção, presença e representação buscando novas formas de relação com a intermidialidade, que vem se tornando uma prática constante ao realizar uma escrita de si poética e inventiva, sem fugir do papel de promover beleza, reflexão ou, pelo menos, inquietação. 


\section{Referências}

ARFUCH, Leonor. O espaço biográfico: dilemas da subjetividade contemporân ea. Rio de Janeiro: Ed UERJ, 2010.

FIGUEIREDO, Eurídice. Mulheres ao espelho: autobiografia, ficção e autoficção. Rio de Janeiro: EdUERJ/FAPERJ, 2014.

KLINGER, Diana. Escritas de si, escritas do outro: o retorno do autor e a virada etnográfica. Rio de Janeiro: 7Letras, 2012.

LEITE, Janaína. Três tentativas de dizer o indizível: a experiência de criação de Conversas com meu pai. São Paulo: Sala Preta, 2014.

LEJEUNE, Philippe. O pacto autobiográfico: de Rousseau à Internet. Belo Hori zonte: Editora UFMG, 2008.

MULLER, Adalberto. Linhas Imaginárias: poesia, mídia, cinema. Porto Alegre: Su lina, 2012.

RANCIÈRE, Jacques. A partilha do sensível. São Paulo: Ed. 34, 2009.

RESENDE, Beatriz. Possibilidades da nova escrita literária no Brasil.

Rio de Janeiro: Revan, 2014.

SANTIAGO, Silviano. "Prosa literária atual no Brasil". In: Nas malhas da letra. Rio de Janeiro: Rocco, 2002. 